\title{
Odilon Redon's noir drawings: characterization of materials and methods using noninvasive imaging and spectroscopies
}

\author{
Nathan S. Daly ${ }^{1}$, Michelle Sullivan² ${ }^{2}$ Lynn Lee ${ }^{1}$, John K. Delaney ${ }^{3}$ and Karen Trentelman ${ }^{1^{*}}$ (1)
}

\begin{abstract}
The artist Odilon Redon (1840-1916) was a French symbolist known for both the dark, surreal prints and drawings he created in the first half of his career, as well as the colorful pastel works that characterized the second half of his career. This study examines two drawings by Redon in the J. Paul Getty Museum collection-Apparition (ca. 1880-1890) and Head within an Aureole (ca. 1894-1895) — executed during the period in his career in which he was transitioning between these two modes. In order to better understand the materials the artist chose and the methods by which he applied them, two noninvasive, macroscopic characterization techniques-macro X-ray fluorescence (MA-XRF) scanning and reflectance imaging spectroscopy (RIS) — were employed. These techniques allowed the materials present to be distinguished and the relationship between their applications visualized. Coupled with fiber optic reflectance spectroscopy (FORS) and Raman microspectroscopy with principal component analysis (PCA), these results give new insight into the materials and methods used by Redon. Six distinct black drawing materials and a yellow pastel were identified in Apparition, underscoring the complexity of Redon's noir drawings. As he began using color pastel more frequently he seemed to use a simplified black palette; in Head within an Aureole the artist used only two black drawing materials and three color pastels (two pink and one blue). This research provides a framework for future noninvasive technical analysis of works by Redon in other collections as well as mixed media drawings more generally.
\end{abstract}

Keywords: Odilon Redon, MA-XRF, Raman microspectroscopy, Reflectance imaging spectroscopy, FORS, Black drawing materials, PCA

\section{Introduction}

The French symbolist Odilon Redon (1840-1916) was known for both his dark, surreal drawings and prints, as well as his vibrant works in color pastel. Throughout the 1870s and 1880s Redon explored the color black in his noir drawings, applying and manipulating materials such as charcoal, black chalk, Conté crayon, and black pastels to achieve a variety of shades and textures within a composition. Beginning around 1880, the artist began to use color pastels to supplement the diversity of black media in his drawings, eventually turning almost entirely to color by the end of the century. Assessment of this

\footnotetext{
*Correspondence: ktrentelman@getty.edu

${ }^{1}$ Getty Conservation Institute, 1200 Getty Center Drive, Los Angeles, CA 90049, USA

Full list of author information is available at the end of the article
}

chronological trend is not entirely straightforward, however, since Redon would occasionally revisit a completed noir drawing, adding passages of color pastel to either highlight elements of the composition or to edit the black media underneath [1]. A better understanding of the shift in the artist's palette over his career could aid in determination of if, and potentially when, subsequent edits and additions were made.

Two drawings in the J. Paul Getty Museum collection, Apparition (ca. 1880-1890) and Head within an Aureole (ca. 1894-1895), were examined to better understand the materials Redon chose to use and the techniques by which he applied them during the transitional period of his career (Fig. 1). Apparition shows a bearded figure below a floating rosette-like feature, surrounded by swirling black shadows. Other than his restrained use of 

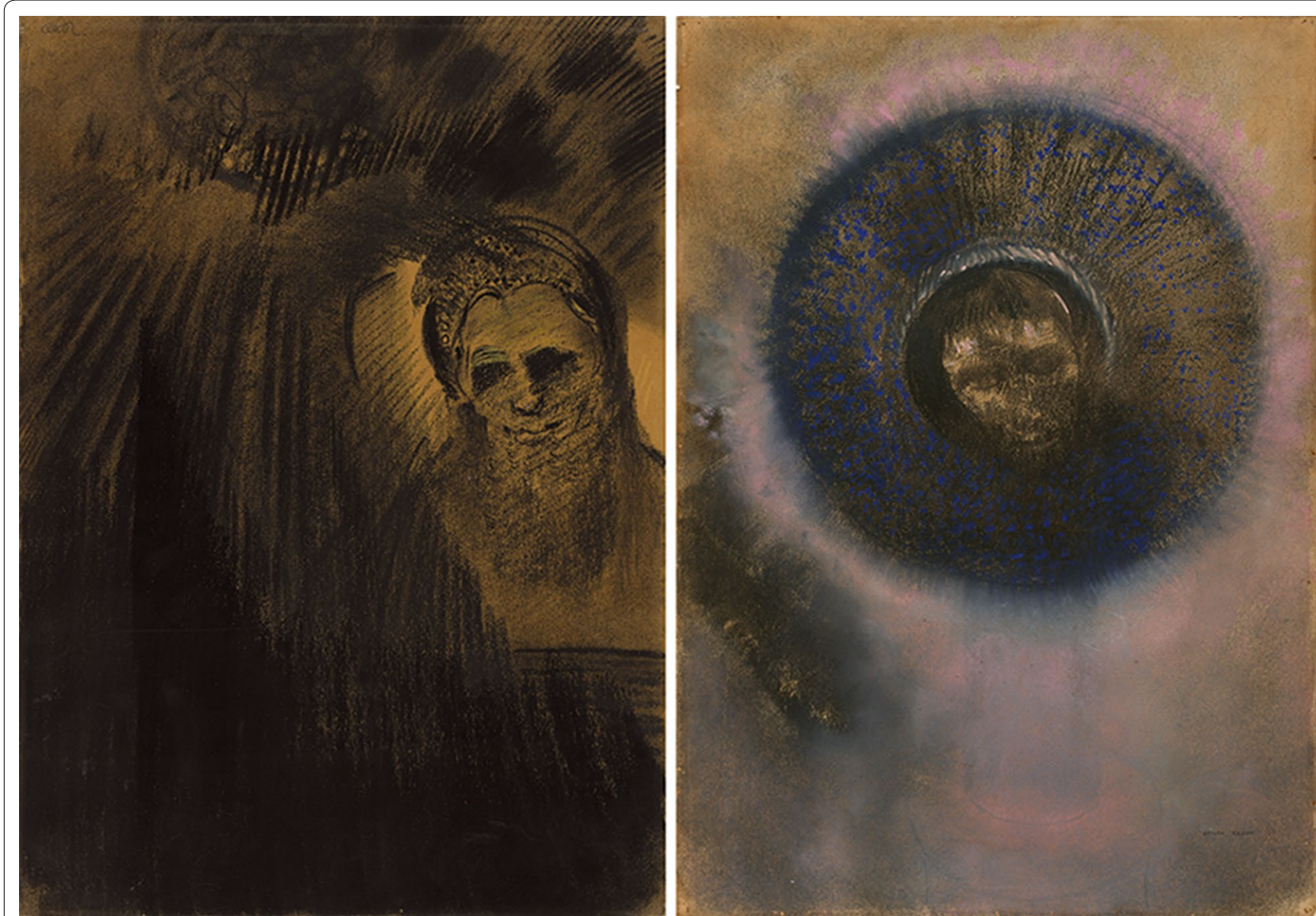

Fig. 1 Two drawings by Odilon Redon in the J. Paul Getty Museum collection. (Left) Apparition (ca. 1880-1890, $52.5 \times 37.3$ cm, JPGM 2013.38), (Right) Head within an Aureole (ca. 1895-1895, $52.0 \times 36.0$ cm, JPGM 2016.10)

yellow pastel highlights, subtly visible against the goldentoned paper, Redon relies entirely on hues of black to achieve differentiation across the composition, placing this drawing squarely in the noir phase of the artist's career. By visual observation this work appears to contain three black drawing materials-a charcoal-like material for background and soft shading, a chalk-like material for sharper details, and a velvety black, pastel-like material for more intense shading. At a glance, the evolution of Redon's method is clear between Apparition and Head within an Aureole. The latter maintains the use of goldenhued paper with multiple tones of black drawing media (in this case a duller charcoal and a darker black pastel or fabricated chalk used to create a floating head and aureole) but also utilizes color in a much more substantial way. Head within an Aureole is dominated by a glowing pink cloud surrounding the black aureole that is itself covered in flecks of vibrant blue pastel.

In the early 1990s, visual analysis of the materials and methods used by Redon was performed on over 300 of his drawings, in some cases complemented by microscopy, infrared reflectography, and the removal of a few targeted samples for further chemical analysis [2]. The results of this extensive study constitute a valuable foundation into the understanding of Redon's materials and techniques. However, since this study was completed, noninvasive methods of chemical and elemental analysis have substantially advanced, including, significantly, macroscale imaging technologies [3-8]. The current study was thus developed to expand upon the earlier foundational work by employing these new technologies, specifically macro X-ray fluorescence (MA-XRF) scanning and reflectance imaging spectroscopy (RIS), as well as site-specific Raman microspectroscopy with principal component analysis (PCA) and fiber optic reflectance spectroscopy (FORS) to study the two selected drawings by Redon. Together, these four noninvasive analytical techniques provide both elemental and molecular information on inorganic and organic components, and serve as a generalized framework for the technical analysis of works by Redon in order to better understand his materials and methods of media application and how they 
changed over the course of his career as an artist. More broadly, this work shows that this research framework could be a powerful tool for analysis of mixed media works on paper in general, even those executed primarily using black drawing materials.

\section{Experimental}

\section{Macroscopic X-ray fluorescence (MA-XRF)}

MA-XRF scanning has increasingly found use in the analysis of paintings and manuscripts $[9,10]$, but has been used less frequently for in situ analysis of works on paper, especially those composed primarily of black (i.e., carbonaceous) drawing materials $[5,7,8,11]$. Though $\mathrm{XRF}$ cannot detect low atomic number $(\mathrm{Z})$ elements like carbon, it can detect higher- $Z$ elements associated with components added to drawing sticks or trace elements in these black pigments [12]. An XRF scanning spectrometer (M6 Jetstream, Bruker Corp.) equipped with a $30 \mathrm{~W}$ rhodium polycapillary tube (operated at $50 \mathrm{kV}$ and $600 \mu \mathrm{A})$ was used to collect MA-XRF maps [13]. Each MA-XRF scan was performed with a spot diameter of $120-450 \mu \mathrm{m}$, step size of $150-420 \mu \mathrm{m}$, and a dwell time of 8-12 ms/step (specific parameters for each scan are noted in the appropriate figure captions). All data were collected using the Bruker ESPRIT software, then fit using a combination of PyMCA and DataMuncher software packages to create 8-bit grayscale element distribution maps [14, 15]. Adobe Photoshop was used to adjust the brightness, contrast, and gamma and to colorize element distribution maps when necessary.

\section{Reflectance imaging spectroscopy (RIS)}

While broadband infrared reflectography and RIS have routinely been used to image black drawing media below the surface of colored materials [16-20], they can also be useful for chemical distinction between iron- and carbon-based black materials [3, 5, 8, 21]. A previously described modified slit-based scanning reflectance imaging spectrometer (SOC710-SWIR, Surface Optics Corp.) was used to collect 256 spectral bands over 910-1770 nm using a Peltier-cooled InGaAs focal plane array for detection [22]. Each drawing was diffusely illuminated using two rheostat-controlled $3200 \mathrm{~K}$ tungsten halogen lamps placed at $\sim 45^{\circ}$ to the surface normal. The image cubes generated were adjusted using a dark image cube and an image cube of a Spectralon panel to correct for the dark offset and non-uniform illumination on the drawings, as well as to convert to apparent reflectance. Black (2\%) and white (99\%) Spectralon standards were used to further improve the calibration using the empirical line calibration function in ENVI v. 5.4 (Harris Geospatial, USA). Individual data cubes were then mosaicked and registered to a high resolution image of the object using a previously described algorithm [20].

\section{Raman microspectroscopy}

Raman spectroscopy has emerged as a leading tool to characterize the crystallinity and chemistry of carbon allotropes ranging from ordered structures such as graphene to more amorphous black materials [23, 24], including most black pigments found in artists' materials-lampblack, bone black, bistre, etc. [25-29]. The authors recently developed a methodology using single wavelength laser excitation and PCA on the entire spectral region around the two broad Raman bands associated with these materials to distinguish carbonaceous artists' materials based on both pigment type and binder content [30]. Raman spectra were collected using a Raman microscope (Invia, Renishaw plc) with $785 \mathrm{~nm}$ laser excitation and a $20 \times$ microscope objective $(\mathrm{NA}=0.4)$ mounted on an extension arm. Spectra were collected over the range of $100-3200 \mathrm{~cm}^{-1}$ using a $1200 \mathrm{l} / \mathrm{mm}$ grating. Relatively low laser power $\left(0.02-0.13 \mathrm{~mW} / \mu \mathrm{m}^{2}\right)$ and short acquisition times (10-60 s) were used to reduce the possibility of damaging the artwork. The $520.5 \mathrm{~cm}^{-1}$ silicon Raman band was used to calibrate all spectra, and cosmic rays were removed as necessary. PCA was performed on Raman spectra of black drawing media using Raman spectra of reference materials and data processing as previously described [30].

\section{Fiber optic reflectance spectroscopy (FORS)}

FORS has become a useful technique for the noninvasive chemical identification of many minerals, synthetic inorganic pigments, as well as some organic materials like red lakes, where fluorescence from organic media interferes with the ability to collect Raman spectra [31-33]. A fiber optics spectroradiometer (FieldSpec4 Hi-Res, ASD Inc.) was used to collect spectral reflectance information on each drawing in the range of 350$2500 \mathrm{~nm}$ with $1.4 \mathrm{~nm}$ and $2.0 \mathrm{~nm}$ spectral sampling over the range of $350-1000 \mathrm{~nm}$ and $1000-2500 \mathrm{~nm}$, respectively. The spectral resolution is reported as $3 \mathrm{~nm}$ at $700 \mathrm{~nm}$ and $8 \mathrm{~nm}$ at $1400 \mathrm{~nm}$ and $2100 \mathrm{~nm}$. The optics fiber was held normal to the artwork, at a distance of $8-10 \mathrm{~mm}$, with the instrument light held at $\sim 45^{\circ}$ to surface normal. Each measurement consisted of 64 accumulations with $8 \mathrm{~ms}$ integration per accumulation. The spectrometer was calibrated against a white (99\%) Spectralon standard. 
Table 1 Summary of material assignments in Apparition and Head within an Aureole

\begin{tabular}{|c|c|c|c|c|c|}
\hline & Color & Material assignment & MA-XRF & Raman & FORS \\
\hline \multirow[t]{7}{*}{ Apparition } & Black 1 & Fabricated chalk & $\mathrm{Fe}, \mathrm{Ca}, \mathrm{Ti}, \mathrm{K}, \mathrm{Si}$ & Carbon & - \\
\hline & Black 2 & Bone black pastel & $\mathrm{Ca}, \mathrm{Fe}, \mathrm{P}, \mathrm{S}$ & Carbon & - \\
\hline & Black 3 & Carbon black pastel & $F \boldsymbol{e}, \mathrm{Ti}, \mathrm{Si}$ & Carbon & - \\
\hline & Black 4 & Carbon black (and aniline black) pastel & $\mathrm{Cu}$ & Carbon & - \\
\hline & Black 5* & Vine charcoal & - & Carbon & - \\
\hline & Black 6 & Compressed charcoal & - & Carbon & - \\
\hline & Yellow & Yellow iron oxide and calcite pastel & $\mathrm{Ca}, \mathrm{Fe}, \mathrm{K}, \mathrm{S}$ & Calcite & Yellow iron oxide \\
\hline \multirow[t]{5}{*}{ Head within an Aureole } & Black A & Carbon black (and aniline black) pastel & $\mathrm{Fe}, \mathrm{Cr}, \mathrm{Pb}, \mathrm{Ca}, \mathrm{Si}, \mathrm{S}$ & Carbon & - \\
\hline & Black B* & Vine charcoal & - & Carbon & - \\
\hline & Pink A & Vermilion and calcite pastel & $\mathrm{Ca}, \mathrm{Hg}, \mathrm{S}$ & Vermilion, calcite & - \\
\hline & Pink B & Alizarin and calcite pastel & $\mathrm{Ca}, \mathrm{S}$ & Calcite & Alizarin \\
\hline & Blue & Ultramarine pastel & $\mathrm{S}, \mathrm{Si}, \mathrm{K}$ & Ultramarine & - \\
\hline
\end{tabular}

Assignments in italics are suggested by analysis rather than confirmed. Materials marked with * were distinguished by infrared RIS with increasing reflectance at longer wavelength. Major elements detected by MA-XRF are in bold italics (see Additional file 1 for spectra)

\section{Results}

A summary of the materials identified in both drawings is presented in Table 1. Select MA-XRF element distribution maps for Apparition and Head within an Aureole are presented in Figs. 2, 3, 4, and 5, respectively, and RIS data are presented in Figs. 6 and 7, respectively. Figure 8 shows the PCA plot employed to differentiate between the Raman spectra of the various black drawing materials identified in the two artworks using reference drawing materials containing carbon-based pigments as a calibration set. Supporting data not shown can be found in Additional file 1 as indicated.

\section{MA-XRF}

For Apparition, the MA-XRF distribution maps for Ca-K, Fe-K, P-K, Cu-K, and Zn-K are shown in Fig. 2 and the maps for Ti-K, Si-K, K-K, and Zn-K of a detail of the head are shown in Fig. 3. As expected, no elements typically detected by MA-XRF could be found in regions presumed to be charcoal based on visual analysis. Both calcium and iron are prevalent in most of the drawing media, but based on an examination of the $\mathrm{Ca}-\mathrm{K} / \mathrm{Fe}-\mathrm{K}$ ratio (upper right image in Fig. 2), together with the phosphorous and copper maps, five additional distinct drawing materials and their locations were identified in Apparition, as will be discussed below.

A sharp, chalk-like material visually identified in the facial features of the figure appears orange in the Ca-K/ Fe-K map in Fig. 2 due to its moderate calcium to iron intensity ratio (Black 1 in Table 1). As seen in Fig. 3, this material also has minor amounts of titanium, potassium, and silicon. This elemental composition is consistent with a drawing material made with a natural black chalk or a fabricated chalk, composed primarily of a carbon-based pigment and kaolin clay $[25,34,35]$. This chalk-like material was used widely across the composition-it can be found in the head and beard of the figure, the details of the rosette, and the majority of the radiating strokes throughout the drawing.

Two other materials - a yellow pastel found in and around the head of the figure, and the matte black passage covering most of the foreground (Black 2) - contain similar amounts of calcium and iron (yellow in Ca-K/ Fe-K map in Fig. 2). Besides their clear visual differences, the yellow pastel contains potassium (Fig. 3) while the black pastel region in the foreground contains significant amounts of phosphorous (Fig. 2), which could be indicative of the presence of bone black in this pastel $[12,36]$.

Another pastel-like black drawing material (Black 3), seen in many of the superficial details of the face and beard of the figure is relatively rich in iron and titanium (see Figs. 2, 3, respectively) with no detectable calcium (red in $\mathrm{Ca} / \mathrm{Fe}$ map in Fig. 2). Significantly, this black also appears to have been used for a partially-obscured shaded passage in the center of the drawing as well as the horizontal line drawn below the figure. Best seen in the Fe-K map in Fig. 2, this line appears to be continuous across the composition, although it has been covered over by another black material on the left side of the drawing.

A third black pastel-like material (Black 4) is identifiable through the detection of minor quantities of copper. The copper distribution map shows that this black was used in both the bold strokes partially covering the rosette and in darkened areas on the sides of the head of the figure (see $\mathrm{Cu}-\mathrm{K}$ map in Fig. 2).

The results from the MA-XRF scans of Head within an Aureole (Ca-K, Fe-K, Cr-K, Hg-L, Pb-L, and $\mathrm{Zn}-\mathrm{K}$ 


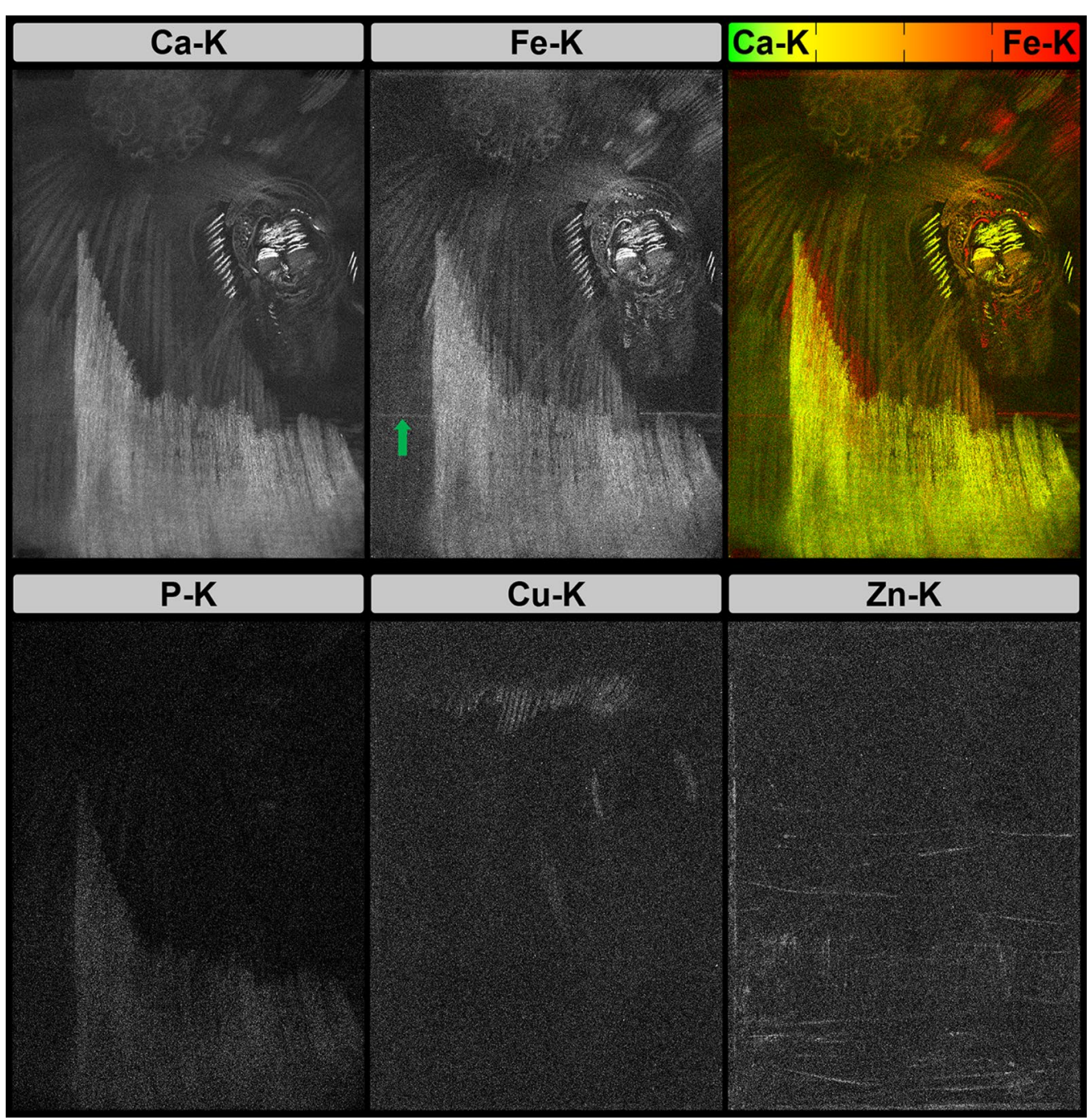

Fig. 2 MA-XRF distribution maps of Ca-K, Fe-K, P-K, Cu-K, and Zn-K in Apparition. Scan parameters: $330 \mu \mathrm{m}$ spot size, $350 \mu \mathrm{m}$ step size, 8 ms dwell time $52.0 \times 37.8 \mathrm{~cm}$ area imaged. An image showing the $\mathrm{Ca}-\mathrm{K} / \mathrm{Fe}-\mathrm{K}$ ratio is presented on a color scale to help visualize those areas containing differing proportions of calcium and iron. The horizontal line seen exclusively in the Fe-K map is highlighted (green arrow)

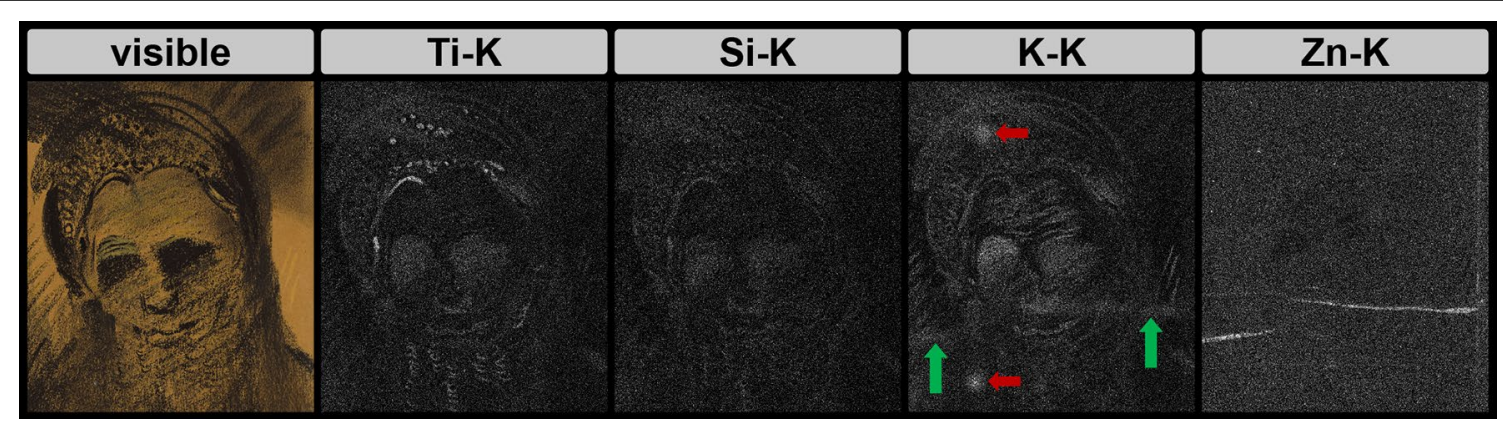

Fig. 3 MA-XRF distribution maps of Ti-K, Si-K, K-K and Zn-K in a detail of Apparition. Scan parameters: $120 \mu \mathrm{m}$ spot size, $200 \mu \mathrm{m}$ step size, $12 \mathrm{~ms}$ dwell time $17.1 \times 14.8 \mathrm{~cm}$ area imaged. The zinc-containing wrinkles seem to also contain potassium (green arrows), while two potassium-containing regions appear uncorrelated to drawing media or zinc (red arrows) 


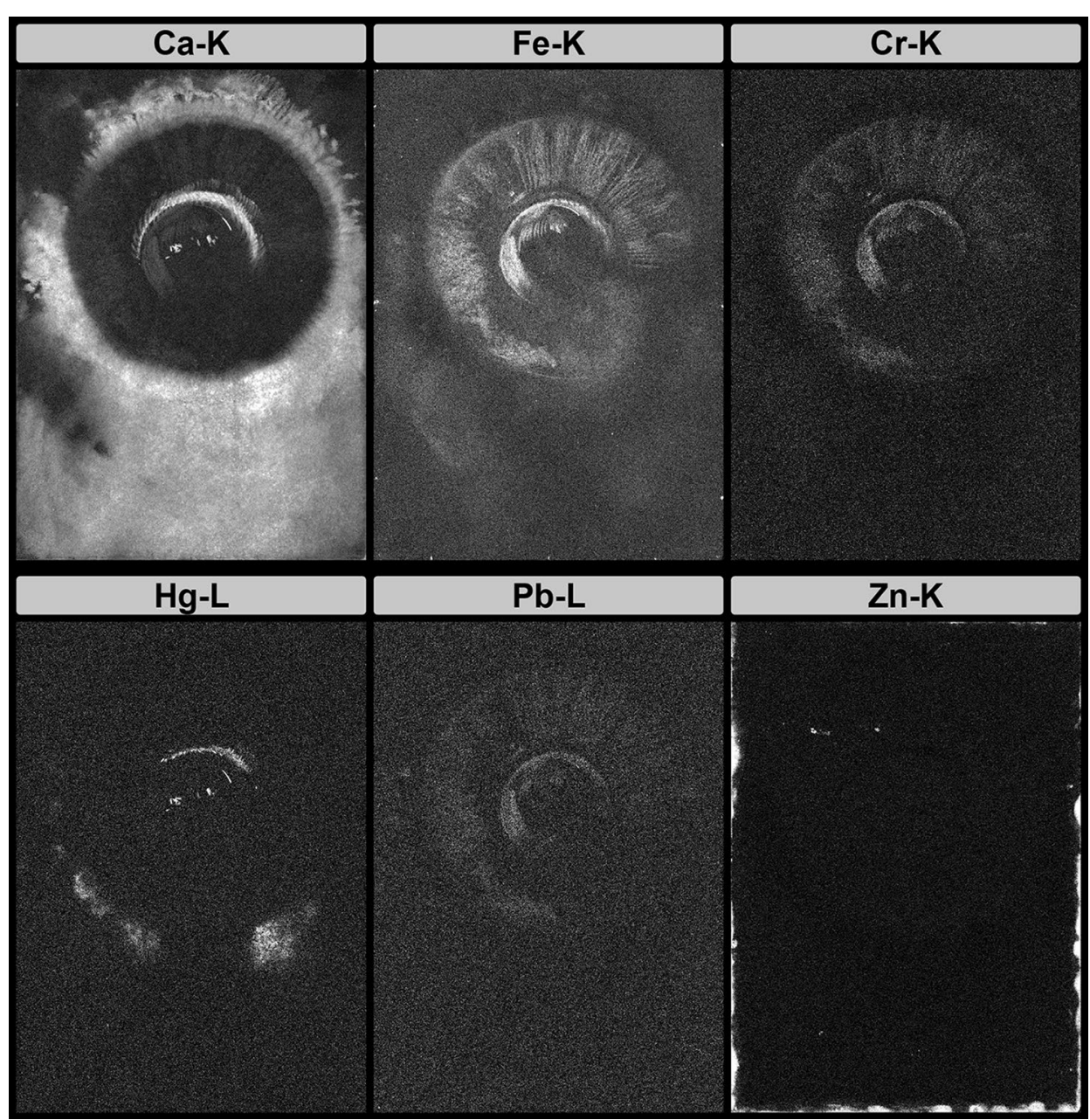

Fig. 4 MA-XRF distribution maps of Ca-K, Fe-K, Cr-K, Hg-L, Pb-L, and Zn-K in Head within an Aureole. Scan parameters: $450 \mu \mathrm{m}$ spot size, 420 um step size, $8 \mathrm{~ms}$ dwell time $52.4 \times 37.2 \mathrm{~cm}$ area imaged

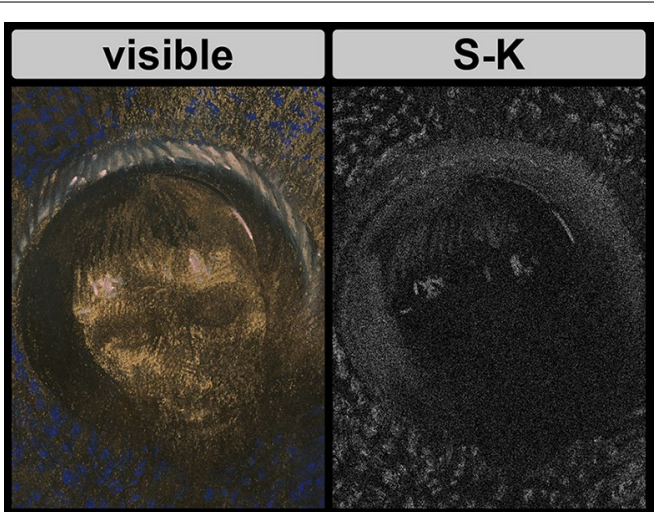

Fig. 5 MA-XRF distribution map of S-K in a detail of Head within an Aureole. Scan parameters: $120 \mu \mathrm{m}$ spot size, $150 \mu \mathrm{m}$ step size, $8 \mathrm{~ms}$ dwell time $17.1 \times 12.7 \mathrm{~cm}$ area imaged maps shown in Fig. 4, and S-K map of a detail of the head shown in Fig. 5) revealed a shift in Redon's choice of materials. A dark black pastel (Black A), found in the hair of the figure and in the strokes in and around the aureole, appears to contain appreciable amounts of iron, chromium, lead, and calcium as well as minor amounts of sulfur and silicon. The materials employed to create the details of the face, the soft areas within the aureole, and the pedestal of the aureole do not appear in any of the element maps generated by MA-XRF, suggesting they are predominantly carbon-based (Black B). While all pink areas of the drawing are rich in calcium, MA-XRF scanning revealed that mercury is present only in select areas of the aureole cloud and in the pink pastel features of the head in the center of the aureole (Pink A), suggesting that Redon used two pink drawing materials to execute 
the composition (see Hg-L map in Fig. 4). The rich blue flecks of pastel in the aureole are detected primarily in the sulfur distribution map with no contribution from calcium (Fig. 5) which, combined with the observation of small uniform particles by microscopy as well as the dating of this artwork to the 1890s, suggest this material likely contains synthetic ultramarine rather than natural lapis lazuli [37, 38].

In both Apparition and Head within an Aureole certain maps show features inconsistent with the application of drawing media, which could be attributed to either the support or fixative applied to the paper. In the case of Apparition both the zinc and potassium distribution maps show features that follow large wrinkles found on the back of the support ( $\mathrm{Zn}$ in Figs. 2, 3 and green arrowindicated regions of $\mathrm{K}$ in Fig. 3). Both these elements can also be found throughout the paper support, with increased signal coming from those areas where the support is wrinkled (and thus slightly more concentrated) suggesting they are components of either the paper itself, its sizing, or the fixative Redon was known to heavily apply to both the front and back of most of his drawings [1]. Zinc could plausibly be found in any of these components, as zinc resinate and zinc sulfate (white vitriol) were common sizing agents in paper [39, 40]. Zinc or aluminum could also be found as an additive to balsam resins [39], which were previously identified in fixative on drawings by Redon using gas-chromatography-massspectrometry (GC-MS) on removed samples $[1,2]$. Since zinc and potassium are both detected in comparable amounts in regions with exposed paper, none of the possible sources of these signals could be ruled out. Additional regions in the potassium MA-XRF distribution maps (red arrow-indicated regions of $\mathrm{K}$ in Fig. 3) are not correlated with zinc and likely originate from a distinct source.
Similarly, in Head within an Aureole the zinc MAXRF distribution map shows elevated signal in regions not consistent with the application of drawing material (see Fig. 4). However, in this case zinc is coincident with chlorine (not shown) rather than potassium and is seen exclusively around the edges of the support, as well as a few isolated regions in the center of the composition. Microscopic examination of these regions revealed gray droplets as the source of the zinc and chlorine signals (see Additional file 1), suggesting this distribution could be caused by fixative, likely a zinc-treated balsam resin as previously noted $[1,2]$. The large pools of zinc-containing media on the front of the drawing could be explained by dispersion of fixative around the edges of the paper from spray application of fixative to the back. Because zinc and chlorine are not found in detectable amounts in areas of the drawing with exposed support, it is not likely that the paper itself or its sizing is responsible for the observed MA-XRF element distribution. This also suggests that in this particular case Redon fixed the back exclusively rather than both sides of the drawing.

\section{RIS}

As shown in Fig. 6, RIS reveals that the soft, matte tonal regions and strokes of Apparition assumed to be a single charcoal-like medium are actually two distinct materials. In the false color infrared reflectogram generated from the RIS data (Fig. 6, center), the body of the figure can be seen to have been filled in with a charcoal slightly browner in appearance (Black 5) than the soft regions in the face and above the head of the figure (Black 6). Under normal viewing conditions both these areas appear black, and it is only through the false-color rendering that their subtle differences could be detected. The false-color image (Fig. 6, center) shows this browner charcoal to have been used in some of the radial strokes on the left
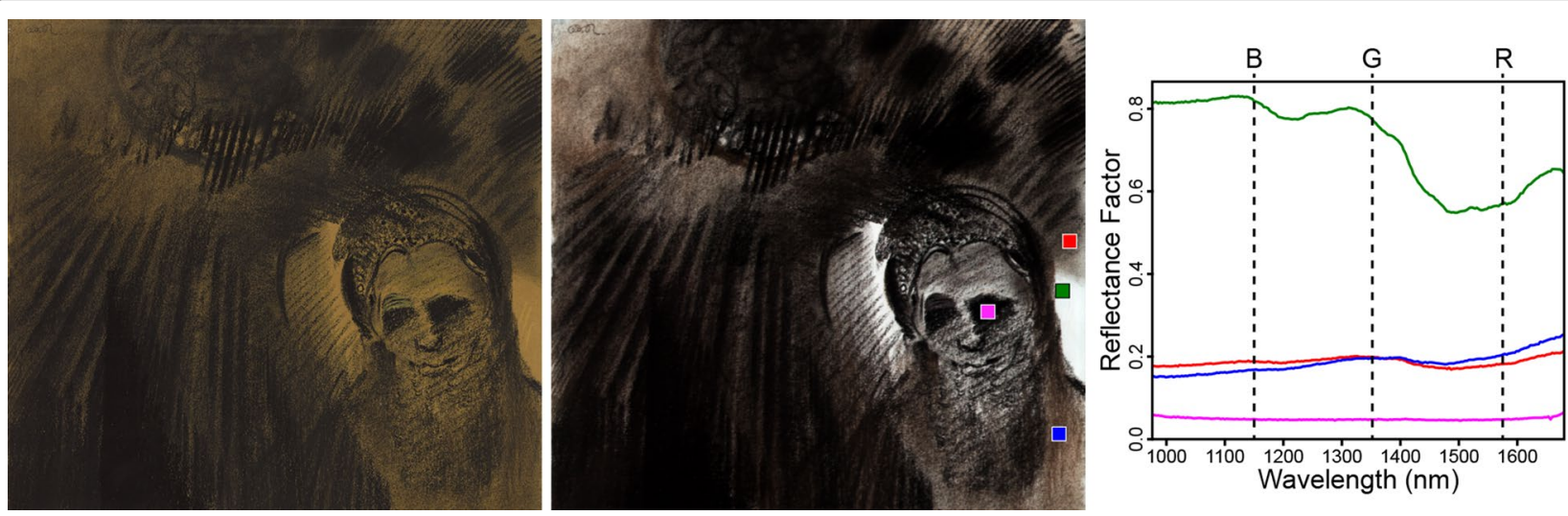

Fig. 6 RIS of Apparition. (Left) Detail color image. (Center) False-color infrared reflectogram created using 1575, 1352, and $1150 \mathrm{~nm}$ bands as RGB channels, respectively. (Right) Plot of spectra from the paper (green), Black 1 (magenta), brown charcoal or Black 5 (blue), and black charcoal or Black 6 (red) 
side of the composition and also to frame the rosette-like object at the top of the drawing. Comparing the spectral features associated with these two charcoals to both the black chalk and bare paper (Fig. 6, right panel) suggests the black charcoal (Black 6, red spectrum) reflects more uniformly across the near infrared compared to the browner charcoal (Black 5, blue spectrum), which reflects longer infrared wavelengths slightly preferentially over shorter wavelength infrared light. While this phenomenon has been reported in copper-based green pigments (not observed by microscopic analysis) and the brown earth pigment umber $[5,8]$, the lack of detectable iron in this medium by MA-XRF does not allow umber to be conclusively identified. This variety of tonal value in charcoal was commonly achieved by using different wood or firing temperatures in their creation, or simply by mixing charcoal with lampblack [41].

The soft, charcoal-like features (Black B) of Head within an Aureole also appear brown compared to the black pastel-like media (Black A) using the same false-color composite of RIS bands, as seen in Fig. 7. While the outline of the head and the strokes of hair remain a deep black in the infrared, the background shaded regions and the facial features appear to reflect more of the longer wavelength infrared light (right panel; spectra in Additional

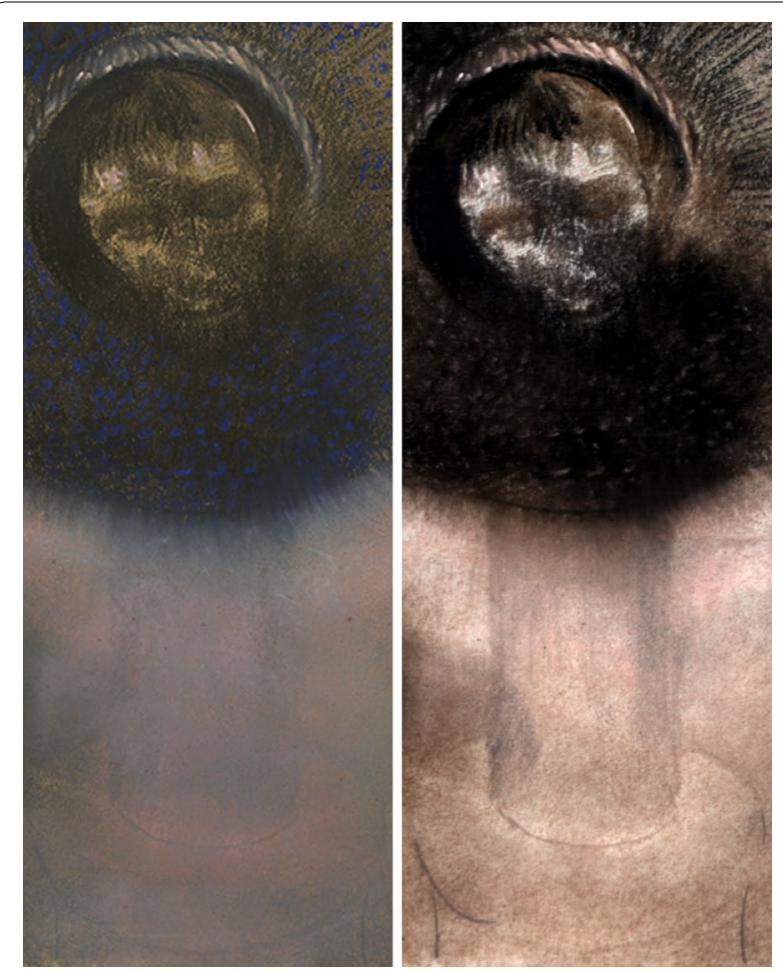

Fig. 7 RIS of Head within an Aureole. (Left) Detail color image. (Right) False-color infrared reflectogram created using 1575, 1352, and $1150 \mathrm{~nm}$ bands as RGB channels, respectively file 1). Additionally, comparing the left and right panels of Fig. 7, the pedestal and neck of the aureole obscured by application of pink media are more clearly visible using infrared RIS.

\section{Raman microspectroscopy}

Each of the drawing materials identified in Apparition and Head within an Aureole using both MA-XRF and RIS (Table 1) were further analyzed using Raman microspectroscopy (see Additional file 1 for representative Raman spectra for each material). While most inorganic pigments present could be identified by their characteristic Raman spectral peaks, carbon-based pigments were identified based on PCA and comparison to reference materials, using the methodology outlined previously [30]. The PCA plot thus generated from Raman spectra of the six black media (Black 1-6) in Apparition and the two black materials (Black A and B) in Head within an Aureole, overlaid on the scores of known reference materials, is shown in Fig. 8. Principal Component 1 (PC1) generally distinguishes between chalks (negative score), soot black-containing drawing media (neutral score), and charcoals (positive score). Principal Component 2 (PC2) is sensitive to organic media content, such as binder and fixative, with a positive score indicating a larger contribution from these components [30]. As such, it should be noted that the position of drawing materials that are more heavily fixed, such as charcoals and chalks employed in earlier stages (Black 1, Black 5, and Black 6 of Apparition and Black B of Head within an Aureole), may have a positively skewed PC2 score compared to the unfixed reference materials analyzed in the PCA plot.

The chalk-like material found in many of the facial features of the figure in Apparition by MA-XRF (Black 1) lies outside the confidence ellipses for the reference materials as shown in Fig. 8. However, the PC1 score, which relates to the form of carbon present, appears to be slightly closer to a fabricated chalk like Conté pencil than a natural black chalk. Inclusion of a historic reference material in this region of the PCA plot could help to more definitively identify this drawing media. By MA-XRF, the dark black pastel in the foreground of Apparition (Black 2) was found to contain both calcium and phosphorous, indicating the pastel could contain the pigment bone black. While the hydroxyapatite peak of bone black located at $961 \mathrm{~cm}^{-1}$ could not be seen by Raman microspectroscopy $[29,42]$, this small peak could be overwhelmed by background fluorescence-in this case caused by either the organic media in the pastel itself or in the fixative Redon was known to apply liberally to both the front and back of his drawings [43]. PCA on the Raman spectra of this material also suggests this pastel is similar to many soot black stick media with low binder content, such as 


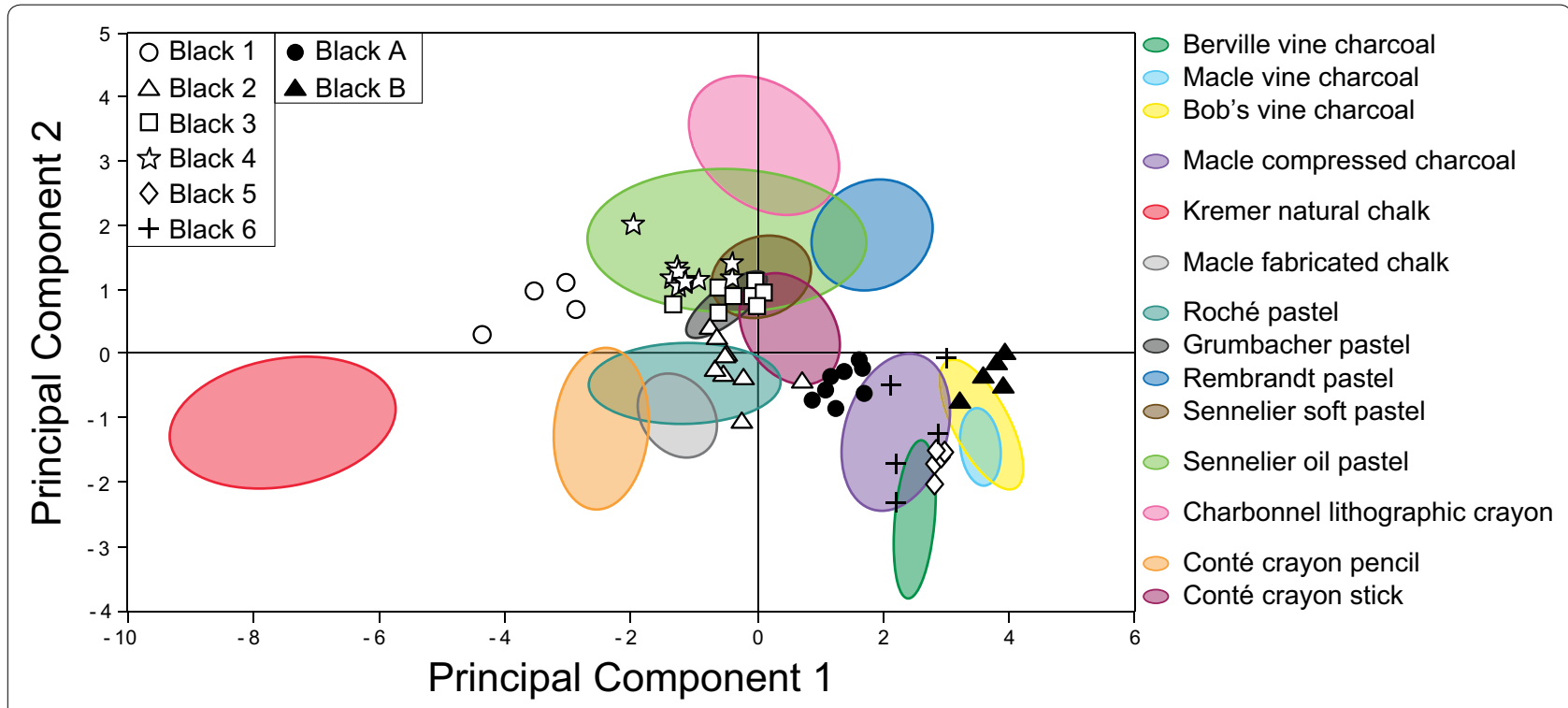

Fig. 8 PCA scores plot of Raman data from Apparition and Head within an Aureole. Labels for the eight types of black media identified in these two drawings are as described in Table 1. Refer to Daly et al. [30] for more information about experimental details for reference drawing media analysis

historic Roché pastel, as seen in Fig. 8. The iron- and titanium-rich black pastel used for the horizontal line and some superficial details of the figure's face in Apparition (Black 3) was observed to have a similar Raman spectrum and aligns well with most carbon soot-containing pastels with moderate binder content such as Grumbacher black pastel (Fig. 8). The copper-containing pastel (Black 4) located in the strokes on the rosette and around the head of the figure has a higher binder-induced background signal in its Raman spectra, supported by its similarity in composition to Sennelier oil pastel by PCA (Fig. 8). The two charcoal-like materials identified in Apparition by RIS were confirmed to be charcoals by Raman microspectroscopy: the brown charcoal present in the beard of the figure and around the rosette (Black 5) appears to be similar to the reference vine charcoals, whereas the black charcoal in the soft areas above the head of the figure (Black 6) is more spectrally similar to compressed charcoal, as seen by the shift in PCA score in Fig. 8. The high iron MA-XRF signal suggests that the yellow pastel in Apparition contains an iron earth pigment, though this could not be observed using Raman microspectroscopy due to a large background signal. However, calcite was identified as a filler in this pastel, being the source of the calcium detected by MA-XRF [44].

In Head within an Aureole the black pastel (Black A) is most similar to binder-poor fabricated sticks like the Conté crayon stick reference rather than any of the three pastels identified in Apparition (Black 2, 3 and 4), and, in fact, lies somewhat closer to compressed charcoal than the reference pastels analyzed (Fig. 8). Inclusion of a historic reference material in this region of the PCA plot could help to more definitively identify this drawing media. The charcoal-like material identified in Head within an Aureole by RIS (Black B), on the other hand, is spectrally similar to vine charcoal, though it appears to differ from the brown charcoal (Black 5) used in Apparition (Fig. 8). Raman microspectroscopy confirmed the presence of vermilion in the pink pastel in strokes on the head as suggested by the mercury MA-XRF element distribution map. On the other hand, Raman microspectroscopy on the pink pastel strokes around the aureole and the pink cloud (Pink B), could only identify calcite in this material, suggesting the use of an organic red in these areas (see "FORS"). Ultramarine was found by Raman microspectroscopy in the blue pastel flecks as suspected from the presence of sulfur observed by MAXRF [42]. This identification is consistent with previous technical analysis on pastel works by Redon, where both ultramarine and Prussian blue were identified by microscopic analysis of removed blue pastel samples [1.

\section{FORS}

Further analysis with FORS was performed on the color pastels for which the colorant could not be identified by Raman microspectroscopy (see Additional file 1 for FORS spectra). FORS analysis suggests that the yellow pastel in Apparition contains iron earth oxide species, most likely goethite $(\alpha-\mathrm{FeOOH})$ found in many yellow iron earth pigments like yellow ochre, though the assignment remains tentative [33, 45]. The pink pastel in Head within an Aureole (Pink B) was found by FORS to contain 
an organic red colorant, though its main absorption feature at $\sim 510 \mathrm{~nm}$ was too broad to be used for identification. However, this sample was found to have an inflection point at $538 \mathrm{~nm}$, suggesting it could be alizarin crimson or cochineal rather than madder [46]. The confirmed presence of calcite, likely as a laking agent or extender, supports the assignment of alizarin crimson, a synthetic alternative to madder first synthesized in 1868 , over cochineal as the colorant in this pastel [47].

\section{Discussion}

\section{Deconstructing Redon's drawing methods}

Taken together, the imaging and spectroscopic data collected in this study have enabled Redon's drawing methods to be reconstructed for these two drawings. In Apparition, Redon utilized a compressed charcoal (Black 6), or possibly a ground and refined charcoal known as sauce de fusain, to tone the background of the composition and to block out the face of the figure [41]. A slightly brown vine charcoal (Black 5) was used to block out the body of the figure and to create a circular shape at the top of the drawing, followed by the creation of the rosette and the majority of the details of the figure using a fabricated chalk (Black 1). Many of the radial strokes around these two objects were created using both of these drawing materials. Additional details of the face, the horizontal line, and some shaded regions in the foreground and the upper right corner of the drawing were executed using an iron-rich black pastel (Black 3). The horizontal line was partially covered using the fabricated chalk, indicating that this black pastel was part of the initial creation of Apparition. Because the yellow pastel, bone black pastel (Black 2) and copper-containing pastel (Black 4) are superficial to all other media, it is unclear whether they were added as finishing touches to the original composition or at a later point in time. Redon used the yellow pastel to add a few radial strokes around the figure and also blended the pastel into the eye and forehead regions of the figure to extend his palette further. The bone black pastel was added to darken the majority of the foreground of the composition, while the copper-containing pastel was employed to darken the sides of the head of the figure and to add strokes over the rosette. Redon achieved this complex layering without disturbing the lower layers by intermittently fixing both the front and back of the drawing, evident both visually and in select MA-XRF element distribution maps.

While the palette of the artist shifted to include more color and fewer black drawing materials in Head within an Aureole, Redon's general technique remained similar to that employed in Apparition. He began by creating the head and toning a circular region around it using a brown-black vine charcoal (Black B), in this case without the aid of compressed charcoal or fabricated chalk. Next a black pastel (Black A) was used to shade around the head and to create the aureole features. The base of the pedestal was drawn with sharper lines than most features of the aureole, though sharpening of either the charcoal or pastel could have achieved this effect. Definitive identification of the material chosen to draw the pedestal using Raman microspectroscopy was not possible due to physical obstruction by the pink wash and the subsequent Raman signal obstruction caused by this material. Redon then used a vermilion pastel (Pink A) to add facial highlights similar to the yellow pastel in Apparition. The mercury distribution map shown in Fig. 4 suggests that this pastel was also used initially to form the pink cloud around the aureole, but was abandoned in favor of the gouache-like alizarin-based material (Pink B) likely applied by pastel wetting. Flecks of blue were added to the aureole during this color application phase using an ultramarine pastel.

\section{Redon's choice of materials}

Odilon Redon is known to have had a great appreciation for the color black, even after his shift towards more and more colorful compositions. Near the end of his life, Redon observed:

"Black is the most essential color...from the matter springs the very vitality of a being, his energy, his spirit, something of his soul, mirror of his sensitivity, residue of his substance, in a way" [48].

While his appreciation for black, and known exploration of many types of drawing media, could explain the unusually large number of black drawing materials identified in Apparition, another possibility is that Redon returned to the drawing at a later date to add some of the more superficial pastel details to the composition. While this distinction is challenging to make, noninvasive macroscopic imaging techniques like MA-XRF and RIS can aid in this process. Drawing materials found in lower layers of the composition are more likely to be part of the initial composition, and it may be possible to further date drawing media application based on the introduction of new synthetic pigments and additives into drawing materials during this era $[41,49]$. Many of these novel materials, such as the vibrant coal-tar colors, quickly fell out of use due to their unfavorable fading, while others were replaced by modified versions with more optimal properties or simply to avoid patent infringement $[50,51]$.

A significant finding of this study is evidence for the use of experimental pigments in both drawings, not only in colored materials but also in black drawing media. In Apparition, the presence of copper in a black pastel (Black 4) that does not appear to contain copper-based 
blue or green pigments by microscopic analysis suggests the use of a synthetic black pigment with this element present as a component of fabrication or processing, such as the coal-tar dye known as aniline black. First patented in 1863, the earliest syntheses of aniline black called for the addition of copper sulfate or copper nitrate to catalyze the polymerization of aniline [52]. By the 1870s, recipes using salts of metals other than copper, such as vanadium or iron, as catalysts became more common and generally included a second reaction with potassium dichromate to reduce the material further and obtain a more permanent black [52]. Some of these typical elements-specifically chromium, iron, and lead-were found in the black pastel used in Head within an Aureole (Black A), hence this material could also contain aniline black. In any case, due to the introduction date of aniline black (1863) compared to the dates for Apparition (ca. 1880-1890) and Head within an Aureole (ca. 1894-1895), its presence cannot be utilized to determine whether these superficial pastel markings were applied to the drawings during their original creation or at a later date. Additional examination of these pastels with Raman microspectroscopy did not reveal the presence of aniline black [53], though it is possible the signal was obscured by the presence of large amounts of sooty black carbon pigment and organic binder. Indeed, by the 1870s aniline black was being used in paints mixed with large amounts of lampblack or ivory black [54]. The presence of aniline black, as well as other organic materials like the fixative, could be more definitively identified by targeted, minimally-invasive analyses such as Fourier-transform infrared spectroscopy or chromatography, which are outside the scope of this work using noninvasive methods of analysis.

\section{Conclusions}

This work demonstrates the benefits of a top-down research framework, whereby macroscopic techniques are employed first for whole-object surveying followed by investigation in areas of interest with site-specific methods, to noninvasively characterize drawing materials in works on paper. This helps ensure unique materials are not overlooked, a risk in the case of drawings like Redon's noirs, where color differences are extremely subtle and there is a possibility that textural similarities across a composition could be achieved by media manipulation. Macroscopic imaging techniques like MA-XRF and RIS can also uncover otherwise inaccessible aspects of an artist's method, such as Redon's preparatory outlining of the horizontal line of Apparition and the pedestal of Head within an Aureole. This work, therefore, not only adds to the limited, but growing, body of studies of drawings on paper using MA-XRF scanning and RIS $[5,7,8,11]$, but significantly, shows the potential of these techniques to distinguish between black drawing materials within a single object based on both pigment-based and accessory chemical makeup. Notably, in Apparition a total of six black drawing materials were identified and mapped across the composition.

Through this research, the array of drawing materials used by Redon, many of which contain synthetic colorants typical of the late nineteenth century, was characterized. Further investigation into when these synthetic colorants became available and their historic recipes, could help in their unambiguous identification in works of art. This could also potentially help determine when they may have been utilized in a specific work of art, especially important with artists such as Redon who were known to rework previously completed objects years later. The work presented here on these two drawings provides a glimpse into this transitional period of Redon's career, but of course is insufficient in scope to draw firm conclusions about how his materials and drawing methods may have changed or evolved. Hopefully, this research framework will be applied by other institutions to create a larger study set, which could further our understanding of Redon's drawing materials and working methods, and aid in the dating of works within his oeuvre.

\section{Additional file}

Additional file 1. Additional figures.

Abbreviations

MA-XRF: macro X-ray fluorescence; RIS: reflectance imaging spectroscopy; FORS: fiber optic reflectance spectroscopy; PCA: principal component analysis.

\section{Acknowledgements}

The authors would like to thank Harriet Stratis for engaging in visual analysis and discussion of both drawings. Additionally the authors are grateful to Douglas MacLennan for assisting in RIS setup and data analysis, as well as Beatriz Fonseca for interpretation of FORS results.

\section{Authors' contributions}

NSD and MS performed visual analysis, MA-XRF, and Raman microspectros copy. NSD analyzed MA-XRF and Raman data. NSD and JKD collected and analyzed RIS and FORS data. NSD wrote the manuscript with contributions and editing by MS, LL, JKD, and KT. All authors read and approved the final manuscript.

\section{Funding}

Not applicable.

Availability of data and materials

Data are available from the authors upon reasonable request.

Competing interests

The authors declare that they have no competing interests. 


\author{
Author details \\ ${ }^{1}$ Getty Conservation Institute, 1200 Getty Center Drive, Los Angeles, CA \\ 90049, USA. ${ }^{2}$ J. Paul Getty Museum, 1200 Getty Center Drive, Los Angeles, \\ CA 90049, USA. ${ }^{3}$ National Gallery of Art, 4th and Constitution Avenue NW, \\ Washington, DC 20565, USA.
}

Received: 29 April 2019 Accepted: 19 June 2019

Published online: 29 June 2019

\section{References}

1. Stratis HK. Beneath the surface: Redon's methods and materials. In: Druick DW, editor. Odilon Redon: prince of dreams. Chicago: The Art Institute of Chicago; 1994. p. 1840-916.

2. Stratis HK. A technical investigation of Odilon Redon's pastels and noirs. In: The book and paper group annual, Vol 14. 1995.

3. Attas M, Cloutis E, Collins C, Goltz D, Majzels C, Mansfield JR, et al. Nearinfrared spectroscopic imaging in art conservation: investigation of drawing constituents. J Cult Herit. 2003;4(2):127-36.

4. Cossairt O, Huang X, Matsuda N, Stratis H, Broadway M, Tumblin J, et al. Surface shape studies of the art of Paul Gauguin. Digit Herit Int Congr. 2015;2015:13-20.

5. Facini M, Dooley KA, Delaney JK, Lomax SQ, Palmer M. Technical exploration of Edgar Degas's Ballet Scene: a late pastel on tracing paper. In: Barbour D, Lomax SQ, editors. Facture: conservation, science, art history, Volume 3: Degas. Washington, DC: National Gallery of Art; 2017.

6. Davari AA, Häberle A, Christlein V, Maier A, Riess C. Sketch layer separation in multi-spectral historical document images. CEUR Workshop Proc. 2016;2021:147-60.

7. Daher C, Sutherland K, Stratis H, Casadio F. Paul Gauguin's Noa Noa prints: multi-analytical characterization of the printmaking techniques and materials. Microchem J. 2018;138:348-59.

8. Dooley KA, Facini M. Revealing Degas's process and material choices in a late pastel on tracing paper with visible-to-near-infrared reflectance imaging spectroscopy. J Am Inst Conserv. 2019;58(1-2):108-21.

9. Dik J, Janssens K, Snickt G, Loeff L, Rickers K, Cotte M. Visualization of a lost painting by Vincent van Gogh using synchrotron radiation based X-ray fluorescence elemental mapping. Anal Chem. 2008;80(16):6436-42.

10. Alfeld M, De NolfW, Cagno S, Appel K, Siddons DP, Kuczewski A, et al. Revealing hidden paint layers in oil paintings by means of scanning macro-XRF: a mock-up study based on Rembrandt's "An old man in military costume". J Anal At Spectrom. 2013;28(1):40-51.

11. Sauvage L, Gombaud C. Liotard's Pastels: techniques of an 18th-century pastellist. In: Studying 18th-century paintings and art on paper. 2015.

12. Shugar NA, Mass LJ. Handheld XRF for art and archaeology. Studies in archaeological sciences. Leuven: Leuven University Press; 2012.

13. Trentelman K, Janssens K, van der Snickt G, Szafran Y, Woollett AT, Dik J. Rembrandt's An Old Man in Military Costume: the underlying image reexamined. Appl Phys A Mater Sci Process. 2015;121(3):801-11.

14. Solé VA, Papillon E, Cotte M, Walter P, Susini J. A multiplatform code for the analysis of energy-dispersive $X$-ray fluorescence spectra. Spectrochim Acta Part B At Spectrosc. 2007:62(1):63-8.

15. Alfeld M, Janssens K. Strategies for processing mega-pixel X-ray fluorescence hyperspectral data: a case study on a version of Caravaggio's painting Supper at Emmaus. J Anal At Spectrom. 2015;30(3):777-89.

16. Baronti S, Casini A, Lotti F, Porcinai S. Multispectral imaging system for the mapping of pigments in works of art by use of principal-component analysis. Appl Opt. 1998:37(8):1299-309.

17. Casini A, Lotti F, Picollo M, Stefani L, Buzzegoli E. Image spectroscopy mapping technique for non-invasive analysis of paintings. Stud Conserv. 1999;44(1):39-48.

18. Ricciardi P, Delaney JK, Facini M, Zeibel JG, Picollo M, Lomax S, et al. Near infrared reflectance imaging spectroscopy to map paint binders in situ on illuminated manuscripts. Angew Chemie Int Ed. 2012;51(23):5607-10.

19. Dooley KA, Lomax S, Zeibel JG, Miliani C, Ricciardi P, Hoenigswald A, et al. Mapping of egg yolk and animal skin glue paint binders in early renaissance paintings using near infrared reflectance imaging spectroscopy. Analyst. 2013;138(17):4838-48.
20. Conover DM, Delaney JK, Loew MH. Automatic registration and mosaicking of technical images of Old Master paintings. Appl Phys A Mater Sci Process. 2015;119(4):1567-75.

21. Delaney JK, Thoury M, Zeibel JG, Ricciardi P, Morales KM, Dooley KA. Visible and infrared imaging spectroscopy of paintings and improved reflectography. Herit Sci. 2016;4(6):1-10.

22. MacLennan D, Trentelman K, Szafran Y, Woollett AT, Delaney JK, Janssens $\mathrm{K}$, et al. Rembrandt's An Old Man in Military Costume: combining hyperspectral and MA-XRF imaging to understand how two paintings were painted on a single panel. J Am Inst Conserv. 2019;58(1-2):54-68.

23. Tuinstra F, Koenig JL. Raman spectrum of graphite. J Chem Phys. 1970;53(3):1126-30.

24. Ferrari AC, Robertson J. Interpretation of Raman spectra of disordered and amorphous carbon. Phys Rev B. 2000;61(20):14095-107.

25. Pagès-Camagna S, Duval A, Guicharnaud H. Study of Gustave Moreau's black drawings: identification of the graphic materials by Raman microspectrometry and PIXE. J Raman Spectrosc. 2004;35(89):628-32.

26. Sadezky A, Muckenhuber H, Grothe H, Niessner R, Pöschl U. Raman microspectroscopy of soot and related carbonaceous materials: spectral analysis and structural information. Carbon NY. 2005:43(8):1731-42.

27. Tomasini EP, Halac EB, Reinoso M, Di Liscia EJ, Maier MS. Micro-Raman spectroscopy of carbon-based black pigments. J Raman Spectrosc. 2012:43(11):1671-5

28. Tomasini EP, Gómez B, Halac EB, Reinoso M, Di Liscia EJ, Siracusano G, et al. Identification of carbon-based black pigments in four South American polychrome wooden sculptures by Raman microscopy. Herit Sci. 2015;3(19):1-8.

29. Coccato A, Jehlicka J, Moens L, Vandenabeele P. Raman spectroscopy for the investigation of carbon-based black pigments. J Raman Spectrosc. 2015;46(10):1003-15.

30. Daly NS, Sullivan M, Lee L, Trentelman K. Multivariate analysis of Raman spectra of carbonaceous black drawing media for the in situ identification of historic artist materials. J Raman Spectrosc. 2018;49(9):1497-506.

31. Bullock $L$. Reflectance spectrophotometry for measurement of colour change. Natl Gall Tech Bull. 1978;2:48-55.

32. Bacci M, Baldini F, Carla R, Linari R. A colour analysis of the Brancacci Chapel frescoes. In: Science, technology and European cultural heritage. 1991. p. 559-62.

33. Aceto M, Agostino A, Fenoglio G, Idone A, Gulmini M, Picollo M, et al. Characterisation of colourants on illuminated manuscripts by portable fibre optic UV-visible-NIR reflectance spectrophotometry. Anal Methods. 2014:6(5):1488-500.

34. Townsend JH. Analysis of pastel and chalk materials. Pap Conserv. 1998;22(1):21-8.

35. McGlinchey C, Buchberg K. The examination of drawings by Georges Seurat using Fourier transform infrared micro-spectroscopy (Micro-FTIR). E-Pres Sci. 2009:6:118-21.

36. Alfeld M, Laurenze-Landsberg C, Denker A, Janssens K, Noble P. Neutron activation autoradiography and scanning macro-XRF of Rembrandt van Rijn's Susanna and the Elders (Gemäldegalerie Berlin): a comparison of two methods for imaging of historical paintings with elemental contrast. Appl Phys A Mater Sci Process. 2015;119(3):795-805.

37. Osticioli I, Mendes NFC, Nevin A, Gil FPSC, Becucci M, Castellucci E. Analysis of natural and artificial ultramarine blue pigments using laser induced breakdown and pulsed Raman spectroscopy, statistical analysis and light microscopy. Spectrochim Acta Part A Mol Biomol Spectrosc. 2009;73(3):525-31.

38. Ricciardi P, Legrand S, Bertolotti G, Janssens K. Macro X-ray fluorescence (MA-XRF) scanning of illuminated manuscript fragments: potentialities and challenges. Microchem J. 2016;124:785-91.

39. Schweizer $V$, Stocks HB. The distillation of resins and the preparation of rosin products, resinates, lamp-black, printing inks, typewriting inks, etc London: Scott, Greenwood and Son; 1917.

40. Bromley HA. Paper and its constituents: a manual of technical methods, chemistry and analysis of raw materials, paper-making fibres, bleaching, sizing, and loading agents and dye-stuffs, microscopy, and physical and chemical properties of papers. London: E. \& F.N. Spon; 1920.

41. Mayhew TD. Dessin au Fusain: nineteenth-century charcoal drawing materials and techniques. In: Hendrix L, editor. Noir: The romance of black in 19th-century french drawings and prints. Los Angeles: Getty Publications; 2016. 
42. Bell IM, Clark RJH, Gibbs PJ. Raman spectroscopic library of natural and synthetic pigments (pre- 1850 AD). Spectrochim Acta Part A Mol Biomol Spectrosc. 1997;53(12):2159-79.

43. Castro K, Pérez-Alonso M, Rodríguez-Laso MD, Fernández LA, Madariaga JM. On-line FT-Raman and dispersive Raman spectra database of artists' materials (e-VISART database). Anal Bioanal Chem. 2005;382(2):248-58.

44. Clark RN. Chapter 1: Spectroscopy of rocks and minerals, and principles of spectroscopy. Manual of remote sensing, volume 3. Remote sensing for the earth sciences. New York: Wiley; 1999.

45. Cornell RM, Schwertmann U. The iron oxides: structure, properties, reactions, occurrences and uses. 2nd ed. Weinheim: WILEY-VCH Verlag GmbH\&Co KGaA; 2003.

46. Fonseca B, Schmidt Patterson CM, Ganio M, MacLennan D, Trentelman K. Seeing red: an improved protocol for the identification of madder- and cochineal-based pigments by FORS. Publication in progress.

47. Kirby J, Spring M, Higgitt C. The technology of eighteenth- and nineteenth-century red lake pigments. Natl Gall Tech Bull. 2007;2007(28):69-95.

48. Redon O, Jacob M, Wasserman JL. To myself: notes on life. Art and Artists: George Braziller; 1986

49. Maheux AF. Degas pastels. Ottawa: National Gallery of Canada; 1988.
50. Morris PJT, Travis AS. A history of the international dyestuff industry. Am Dyest Report. 1992;81(11):59-100.

51. Lomax SQ, Learner T. A review of the classes, structures, and methods of analysis of synthetic organic pigments. J Am Inst Conserv. 2006:45(2):107-25.

52. Lightfoot JE. The chemical history and progress of aniline black. Brumley; 1871.

53. Chua L, Hoevel C, Smith GD. Characterization of Haku Maki prints from the "Poem" series using light-based techniques. Herit Sci. 2016;4(25):1-11.

54. Riffault des Hêtres JRD, Vergnaud AD, Toussaint GA, Fesquet AA. A practical treatise on the manufacture of colors for painting. In: Malepeyre F, editor. Comprising the origin, definition, and classification of colors; the treatment of the raw materials etc. Philadelphia: H.C. Baird; 1874.

\section{Publisher's Note}

Springer Nature remains neutral with regard to jurisdictional claims in published maps and institutional affiliations. 